\title{
Creation of digital educational environment for police leaders
}

\author{
Elena Radchenko ${ }^{1, *}$, Mikhail Kozin ${ }^{1}$, and Galina Pyrchenkova ${ }^{2}$ \\ ${ }^{1}$ Federal State Research Institute of the Federal Penitentiary Service of the Russian Federation, \\ 125130, Moscow, Russian Federation, Moscow, Narvskaya str., 15 A \\ ${ }^{2}$ Academy of Management of the Ministry of Internal Affairs of Russia, 125171, Moscow, Russian \\ Federation, Moscow, Z. and A. Kosmodemyansky str., 8
}

\begin{abstract}
The article is devoted to the problems of creating a successful digital educational environment in a higher educational institution. The issues of interactive communication between teachers and students in virtual space using computer and information and communication technologies are considered. The article describes the advantages and disadvantages of creating a digital educational environment at the Academy of Management of the Ministry of Internal Affairs of Russia. The authors analyze the assessment of the organization and content of the distance learning course from the point of view of the representatives of the teaching staff. The objectives of the study include studying the issue of the level of readiness of the teachers of the educational organization to conduct training sessions in a distance mode, as well as the analysis of the degree of the students' self-organization and their abilities for the independent acquisition of knowledge in a remote access mode. During the study, considerable attention is paid to the study of problematic aspects of creating a digital educational environment in a higher educational institution and the search for possible ways to overcome them.
\end{abstract}

\section{Introduction}

The modern professional community needs experts who have not only fundamental knowledge and practical skills in their application, but also the ability to improve their educational potential and professional level, using the resources of the information and communication system and distance learning technologies. Strategic objectives for the development of innovative foundations for teaching educational programs in higher education institutions are defined in the Decree of the President of the Russian Federation No. 204.

In the context of the need to achieve the national goals, the Academy of Management of the Ministry of Internal Affairs of Russia (hereinafter referred to as the Academy) has worked out a program for the development of the educational organization until 2024, one of the key areas of which is the creation of a digital educational environment for police leaders. Along with the development of innovative foundations for teaching master's degree

\footnotetext{
* Corresponding author: helenr2003@mail.ru
} 
programs, training highly qualified personnel and providing additional professional education, the program is aimed at creating a new generation of teachers who are real experts in modern digital learning technologies. Considering the fact that the Academy is the leading center of the departmental management education and science, the experience of organizing digital educational environment for police leaders at the Academy acquires additional relevance.

\section{Problem statement}

Responding to the challenges of the modern information and educational space, Russian scientists are actively exploring the development and implementation of innovative elearning technologies in higher education institutions of the country: Skorikova, Khromov \& Dneprovskaya (2016), Lomonosova (2018). Many authors point to the fact that it is the rapid growth of the informatization of the Russian society that prompts the representatives of the scientific and pedagogical community to look for innovative ways of organizing the educational process and interacting with students: Urintsov, Dik \& Dneprovskaya (2014).

Analysis of special studies in this area has showed that Russian scientists consider higher e-education, mainly, as an innovative educational process that provides interactive communication between teachers and students in a virtual space using computer and information and communication technologies, aimed at the development of cognitive and creative abilities of students, as well as the ability to independently master new ways of acquiring knowledge.

Currently, the issues of creating a high-quality digital educational environment in the higher education system are also in the center of attention of the world scientific and pedagogical community. Foreign scientists focus on various approaches to organizing a digital educational environment, improving the quality of distance learning, developing innovative e-learning technologies: Bleik (2015), Göransson \& Nilholm (2014), Nawaz \& Muhammad (2012), Mohr, Holtbrügge \& Berg (2012), Peters \& Jandric (2017), Schneider (2018), Tsai \& Tsai (2018). At the present stage of development of information and communication technologies in the educational sphere, foreign scientists are actively studying the optimal conditions for the use of electronic educational resources in the system of mixed (traditional and distance) education of university students: Jones \& Sharma (2017), Wang \& Huang (2018), Baragash \& Al -Samarraie (2018) et al.

However, despite the considerable interest of scientists in the problems of creating a successful digital educational environment in a higher education institution, the issues of organizing e-learning that meets the needs of students and the requirements of the scientific and pedagogical community have remained insufficiently studied in the Russian and foreign specialized literature.

\section{Research questions}

For a number of years, the Academy has been developing distance learning technologies, which are used in the implementation of basic and additional programs of higher professional education: a material and technical base for distance learning was created; educational and methodological support was developed and placed in the electronic educational environment; a division responsible for the implementation of educational Internet technologies was formed. Besides, the continuous work is underway to prepare the teaching staff and students of the Academy to work in a distance learning mode.

It should be noted that in the system of higher education of the Ministry of Internal Affairs of Russia, the Academy is the initiator of entrance examinations based on the use of 
distance technologies. The admission company takes place in three stages: 1) collecting data on candidates and forming their electronic files; 2) conducting remote admission tests; 3) data processing and submission to the selection committee. Admission tests include automated testing and videoconferencing interviews. Candidates for training who have successfully passed the test are allowed for the interview. The purpose of the interview is to identify the intellectual potential of the applicant for the successful mastering of the educational program, his or her communication and leadership qualities, motivation and value system. Before the entrance examinations, online consultations are held for candidates for training.

Today, the Academy has four years of positive experience in conducting the admission company remotely, which not only has reduced its cost for the Ministry of Internal Affairs, but also allowed numerous employees to continue serving without being distracted from solving professional problems. In this regard, it should be mentioned that representatives of other educational organizations of the Ministry of Internal Affairs have repeatedly visited the Academy in order to study and further use this positive experience recommended for the use in the departmental educational organizations by the Department of Civil Service and Personnel of the Ministry of Internal Affairs of the Russian Federation.

To provide departmental educational organizations with distance learning technologies, the Ministry of Internal Affairs of the Russian Federation has deployed the world's largest federal information and communication video conferencing system based on the innovative software solution of the Russian company TrueConf, which is capable of providing highquality video communications to 1 million subscribers, including employees of internal affairs bodies in remote regions of Russia. The development and commissioning in 2014 of such a specialized video conferencing system was due to the need to create a centralized closed departmental system with a high level of security and stable operation. Using the capabilities of the TrueConf telecommunication system made it possible to organize an interactive exchange of text and audio-video information between the teaching staff of the Academy and the students.

Nevertheless, during the total transition to distance learning in the context of the coronavirus pandemic the teaching staff of the Academy has faced a number of problems. It became necessary to determine not only the positive aspects of organizing the digital educational environment for police leaders, but also to answer the questions: Is the level of development of the information technologies infrastructure of the Academy sufficient for technical support of distance learning for police leaders? Do educators have the necessary skills to work in the digital learning environment? Does distance learning lead to a fullfledged mastering of the educational program? Is it possible to effectively use teaching materials developed by teachers for classroom lessons in a distance mode? Is it possible to ensure high-quality pedagogical control of the knowledge acquired by the students? What problems need to be solved to improve the quality of distance learning? etc.

\section{Purpose of the study}

This study is a continuation of the investigation of the positive and problematic aspects of organizing a high-quality digital educational environment that meets the expectations and needs of the Academy teachers and students. The authors focus on assessing the content of the distance learning course, the effectiveness of the implementation of the educational program in the remote access mode from the point of view of the teaching staff of the Academy. The objectives of the study also include studying the issue of the level of readiness of teachers of an educational organization to conduct lectures, seminars and practical classes in a distance mode. The authors will try to analyze the degree of the 
students' self-organization and their abilities for the independent acquisition of knowledge in a remote access mode.

\section{Research methods}

To determine the positive aspects and problems of organizing a high-quality digital educational environment for police leaders in the context of a complete transition to distance learning, a pedagogical experiment (questionnaire survey) was conducted, during which 24 teachers of the Academy were interviewed in the videoconference mode. In the course of the experiment, an unstructured survey of the respondents was also conducted to identify the most important, in their opinion, advantages and disadvantages of the forced transition to distance learning, the results of which are graphically displayed in this study.

Data collection and analysis were carried out using a questionnaire developed on the basis of the Likert scale, including 10 items. In the course of the questionnaire study, when working with this scale, pedagogical workers assessed the degree of their agreement or disagreement with each judgment, from 1. - excellent, 2. - very good, 3. - good, 4. satisfactory, 5. - unsatisfactory. Such a point assessment (rating) scale made it possible to determine the attitude of each teacher for each individual question. The sum of the assessments of each individual judgment made it possible to reveal the overall assessment of the representatives of the teaching staff of the Academy of any issue.

The results of the study are reflected in the table below.

Table 1. Evaluation of the distant implementation of the educational program by the teaching staff of the Academy of Management of the Ministry of Internal Affairs of Russia.

\begin{tabular}{|c|c|c|c|c|c|}
\hline Statement & $\begin{array}{l}\text { Excelle } \\
\text { nt }\end{array}$ & $\begin{array}{l}\text { Very } \\
\text { good }\end{array}$ & Good & $\begin{array}{r}\text { Satisf } \\
\text { actory }\end{array}$ & $\begin{array}{l}\text { Unsatisfactor } \\
\mathbf{y}\end{array}$ \\
\hline $\begin{array}{l}\text { 1. The implementation of the } \\
\text { educational program in the distance } \\
\text { mode, in general, has passed ... }\end{array}$ & $14 \%$ & $62 \%$ & $13 \%$ & $11 \%$ & - \\
\hline $\begin{array}{l}\text { 2. The organization of the distance } \\
\text { learning course can be assessed as ... }\end{array}$ & $9 \%$ & $56 \%$ & $25 \%$ & $10 \%$ & - \\
\hline $\begin{array}{l}\text { 3. The content of educational and } \\
\text { methodological material for } \\
\text { conducting training sessions and video } \\
\text { lectures can be assessed as ... }\end{array}$ & $3 \%$ & $22 \%$ & $54 \%$ & $21 \%$ & - \\
\hline $\begin{array}{l}\text { 4. The content of educational and } \\
\text { methodological material for } \\
\text { independent work can be assessed as } \\
\text {... }\end{array}$ & $27 \%$ & $52 \%$ & $17 \%$ & $4 \%$ & - \\
\hline $\begin{array}{l}\text { 5. The effectiveness of the use of } \\
\text { multimedia tools for the presentation } \\
\text { of educational material can be assessed } \\
\text { as ... }\end{array}$ & $4 \%$ & $31 \%$ & $44 \%$ & $21 \%$ & - \\
\hline $\begin{array}{l}\text { 6. The level of the teacher's readiness } \\
\text { to conduct lectures, seminars and } \\
\text { practical classes in a distance mode, in } \\
\text { general, can be assessed as ... }\end{array}$ & - & $25 \%$ & $49 \%$ & $26 \%$ & - \\
\hline $\begin{array}{l}\text { 7. The level of self-organization of } \\
\text { students in the process of mastering } \\
\text { the educational program in the } \\
\text { distance mode, in general, can be } \\
\text { assessed as ... }\end{array}$ & - & $36 \%$ & $47 \%$ & $17 \%$ & - \\
\hline $\begin{array}{l}\text { 8. The degree of formation of } \\
\text { students' skills of independent } \\
\text { acquisition of knowledge in a distance } \\
\text { mode, in general, can be assessed as ... }\end{array}$ & - & $15 \%$ & $29 \%$ & $56 \%$ & - \\
\hline
\end{tabular}




\begin{tabular}{|l|l|l|l|l|l|}
\hline $\begin{array}{l}\text { 9. Pedagogical control of the current } \\
\text { and final progress of students in the } \\
\text { distance learning course can be } \\
\text { assessed as ... }\end{array}$ & $3 \%$ & $13 \%$ & $54 \%$ & $30 \%$ & - \\
\hline $\begin{array}{l}10 . \quad \text { The degree of mastering the } \\
\text { educational program by students in the } \\
\text { distance mode can be assessed as ... }\end{array}$ & $18 \%$ & $51 \%$ & $23 \%$ & $8 \%$ & - \\
\hline
\end{tabular}

\section{Findings}

As shown in the table above, the overwhelming majority of the teachers of the Academy (76\%) expressed the opinion that the implementation of the educational program in the distance mode, in general, was successful and can be assessed as "excellent" and "very good", which indicates a relatively a sufficient level of readiness of an educational organization to switch to a remote mode of work in an extreme situation. The majority of teachers $(65 \%)$ also rated the organization of the training course as "excellent" and "very good". However, the remaining respondents (24\%) rated the level of implementation of the educational program in a remote mode as "good" and "satisfactory", which requires from the academic staff to revise a number of organizational issues in order to develop appropriate decisions. This is also evidenced by the assessments of $35 \%$ of the respondents who believe that the organization of the training course was less successful and deserves marks "good" (25\%) and "satisfactory" (10\%).

The fact that $75 \%$ of the respondents rated the content of educational and methodological material for conducting training sessions and video lectures as "good" and "satisfactory" cannot be ignored. Only less than half of the teachers $(25 \%)$ expressed their satisfaction with the content of the educational and methodological material for conducting training sessions and video lectures, assessing it as "excellent" and "very good". This result is due to the fact that most of this material was developed for teaching in the classrooms of the Academy. Thus there is the task set before the teaching staff of the Academy to substantially revise educational and methodological material for conducting training sessions and video lectures, taking into account the requirements of e-learning, including the reduction of the time of conducting classes in a remote mode, psychological characteristics of the distant perception of educational information by the students, increased level of independent acquisition of new knowledge by the students, changing the role of the teacher in the educational process, etc.

At the same time, the questionnaire survey has showed a high assessment of the effectiveness of teaching materials aimed for independent work, developed by the teachers for a distance learning course: $79 \%$ of the teachers rated them as "excellent" and "very good". Nevertheless, the teaching staff should definitely pay attention to the fact that more than half of the respondents $(65 \%)$ assessed the effectiveness of the use of multimedia presentation of educational material while conducting practical classes, seminars and lectures in a remote mode at a relatively low level: "good" (44\%) and "satisfactory" (21\%).

Despite the work organized by the management of the Academy to instruct teachers to work remotely, the study has showed that, in general, teachers did not evaluate their readiness to work remotely at a high level. As it is shown in the table, only $25 \%$ of the respondents rated their readiness to work in remote access mode as "very good". At the same time, $75 \%$ of the respondents believe that the degree of their readiness to work in remote mode can be assessed only as "good" and "satisfactory", which necessitates further search for solutions to improve the level of teachers' training to work in a remote mode.

The pedagogical control of the current and final progress of the students in the distance learning course has received relatively high marks from the teachers: $67 \%$ of the respondents gave marks "very good" and "good". However, only 3\% of the teachers 
evaluated the level of the pedagogical control as an "excellent" one, and $30 \%$ of the respondents rated it as "satisfactory"/ These results demonstrate an insufficient degree of the development of the assessment tools for monitoring students' knowledge and formation of their educational and professional competencies.

One of the most important component of the implementation of the educational program in the distance mode is the readiness of the students themselves to study in a remote mode. In this regard, it is important to assess the level of self-organization of the students in the process of distant mastering educational program and the degree of formation of their skills of independent acquisition of knowledge. As it can be seen from the table reflecting the results of the study, these indicators leave much to be desired. More than half of the interviewed teachers rated: 1) the level of self-organization of the students in the process of mastering the educational program in the distance mode as "good" $(47 \%)$ and "satisfactory" $(17 \%) ; 2)$ the degree of formation of the students' skills of independent acquisition of knowledge in the distance mode as "good" (29\%) and "satisfactory" (56\%). The results obtained indicate that not all the students demonstrate a sufficient level of conscious attitude to distance learning and motivation to obtain high educational results.

At the same time, the marks received by the students during the intermediate and final examination allowed the teachers, in general, to recognize the degree of remote mastering the educational program by the students as quite effective: $18 \%$ of the respondents rated it "excellent", $51 \%$ of the respondents rated it "very good". Nevertheless, from the authors' point of view, such a high assessment cannot be recognized as absolutely objective, since, to a certain extent, it is also the result of the insufficient development of evaluative means of pedagogical control, which has been already mentioned above in this article.

During the experiment, an unstructured survey of 24 representatives of the teaching staff was also conducted. The teachers were asked to identify three the most important advantages and disadvantages of mastering the educational program in the distance mode from the following list:

advantages:

- a new role of the teacher - the coordinator of the educational process;

- lack of time and space restrictions;

- a high degree of self-organization and independence of students;

- creation of conditions for independent acquisition of new knowledge by students;

- an opportunity for students to continue their studies without interrupting their professional duties;

- the ability for students to determine the speed of learning the material, corresponding to the peculiarities of

thinking;

- increasing the level of students' responsibility for learning outcomes.

disadvantages:

- impossibility of implementing a dialogue between a teacher and students, adopted in the traditional form of

education;

- lack of sufficient pedagogical control of the knowledge acquired by the students;

- reduction of the volume of educational material and time for its study;

- lack of appropriate training of teachers;

- lack of interpersonal communication during the lesson and opportunities to compare the results of their

learning with the results of other participants in the group;

- lack of a high-quality video conferencing during the periods of the high server load;

- unavailability of the regulatory framework;

- an increase in intellectual, physical and mental stress. 
The results of the study are shown graphically in figures 1 and 2.

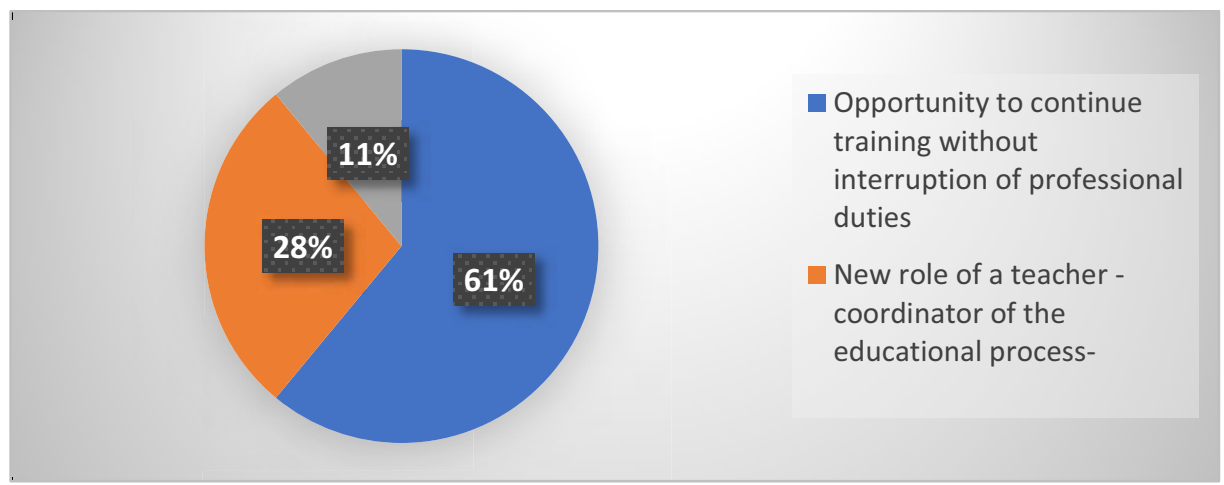

Fig. 1. The most important advantages of creating a digital educational environment for police leaders from the point of view of the teachers of the Academy of Management of the Ministry of Internal Affairs of Russia.

As it can be seen from the above diagram, the representatives of the teaching staff of the Academy considered the possibility of organizing the educational process without interrupting students from their professional duties as the most valuable advantage of creating a digital educational environment for police leaders ( $61 \%$ of the respondents).

Among the most important advantages of e-learning, the teachers also identified the opportunity to participate in the educational process as a coordinator of educational activities (28\% of the respondents). It should be noted that the organization of joint educational activities (partnership between a teacher and students in the course of educational activities) is in full compliance with the andragogical principles of adult education and is a necessary condition for improving the quality of the formation of general educational and professional competencies of police leaders in a higher education institution.

In the course of the survey, $11 \%$ of the respondents pointed out the possibility of creating conditions for students to independently acquire new knowledge as one of the most important advantages of organizing a digital educational environment for police leaders. From our point of view, this is another confirmation of the statement made by the Russian researcher, who identified distance learning as the most adequate process for implementing the principle of lifelong education (Suvorova (2014)). 


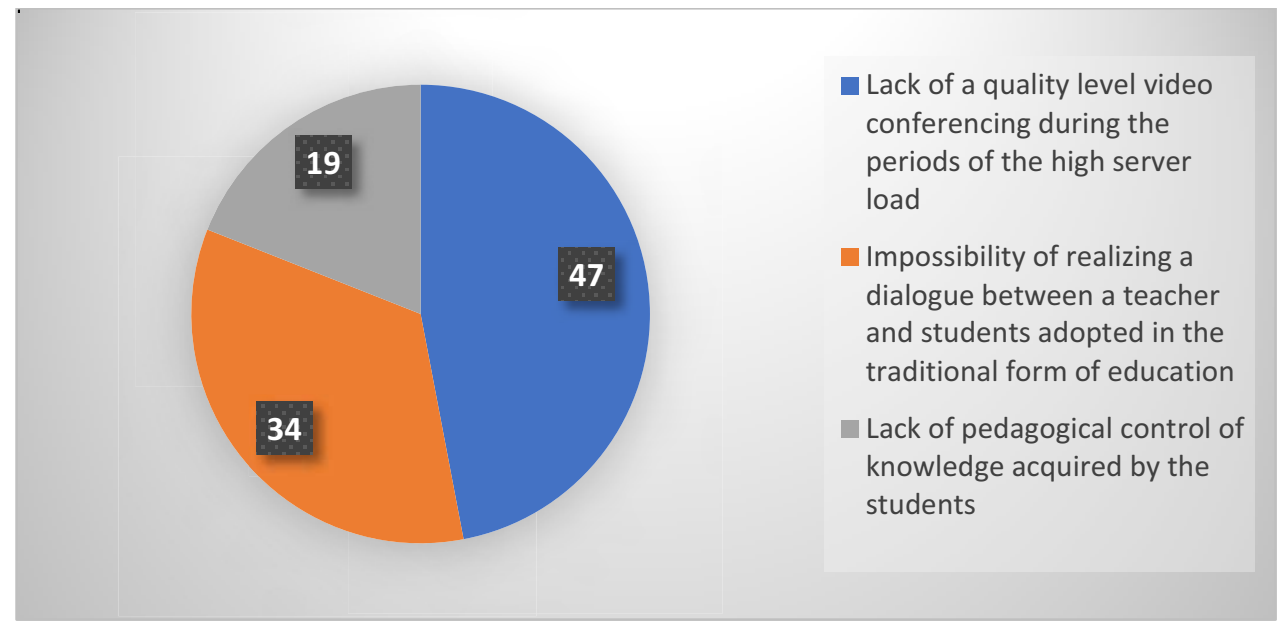

Fig. 2. The most important disadvantages of creating a digital educational environment for police leaders from the point of view of the teachers of the Academy of Management of the Ministry of Internal Affairs of Russia.

As it can be seen from the diagram in figure 2, the Academy teachers indicated the lack of a high-quality level of video conferencing during the periods of high server load as one of the most important disadvantages of creating a digital educational environment for police chiefs $(47 \%$ of the respondents). The other two negative aspects of creating a digital educational environment for police leaders include the impossibility of realizing a dialogue between a teacher and students, adopted in the traditional form of education (34\% of the respondents) and lack of the sufficient pedagogical control of the knowledge received by the students (19\% of the respondents).

Thus, it becomes obvious that the problem of ensuring the stable functioning of the information and communication system of video conferencing still remains relevant for creating a successful digital educational environment in any higher education institution. On the other hand, the results obtained make it necessary to develop an innovative model for the transfer of educational information in a remote mode, designed to ensure an organic and emotionally colored relationship of all the participants of the educational process. Particular attention should be paid to the development of a control system for the assessment of the students' educational results and the evaluation of the level of formation of their educational and professional competencies within the framework of distance learning.

\section{Conclusions}

The need to organize the transition to distance learning as soon as possible in connection with the pandemic has opened the way for rethinking educational technologies and made it possible to achieve significant progress in the field of digital learning. At the same time, in contrast to the systematically organized online learning and blended learning, which includes traditional and distance learning methods, the emergency transition to distance learning in a pandemic has revealed significant problems that require new approaches to their solution.

The experience gained in the emergency organization of e-learning for the students of the Academy allowed 
us to conclude that in order to overcome the problems of creating a successful digital educational environment for police leaders and, in general, to improve the quality of distance education, it is necessary to solve the following tasks:

- to ensure a stable level of functioning of the information and communication system of video conferencing to create an effective digital educational environment of a higher education institution;

- to revise the educational and methodological material for practical classes, seminars and video lectures, taking into account the requirements of e-learning;

- to provide conditions for improving the level of training of teachers to work in a distance mode;

- to create effective models of multimedia presentation of educational materials for a distance learning course;

- to develop a system of pedagogical control for monitoring and evaluating students' educational results within the framework of distance learning;

- to develop methods of increasing the level of self-organization of students to form their skills for independent acquisition of knowledge and motivation to obtain high educational results.

Summing up, it should be recognized that the experience of emergency organization of e-learning for the students of the Academy of Management of the Ministry of Internal Affairs of Russia has not only changed the idea of the forms and models of education provision in the future, but also has made it possible to identify problematic issues of creating a digital educational environment in a higher education institution and outline some ways of their solution.

\section{References}

1. N. Matveeva, I. Abramova, A. Ananyina, E. Shihmolina, N. Medvedeva, I. Mazaeva, A. Korenev, N. Tsvetkova, The magic of innovation. New techniques and technologies in teaching foreign languages (London, Cambridge press, 2015)

2. T. P. Skorikova, S. S. Khromov, N. V. Dneprovskaya, Distance learning in scientific and professional fields of communication (interdisciplinary approach). Internet Journal of Environmental Science Education, 11(10), 3467-3476 (2016)

3. N. M. Lomonosova, Digital learning resources: Enhancing efficiency within blended higher education. Novosibirsk State Pedagogical University Bulletin, 8(6), 124-137 (2018) http://en.vestnik.nspu.ru (Last accessed 11.05.2020) DOI: 10.15293/22263365.1806 .08 .

4. A. Urintsov, V Dik, N. Dneprovskaya, Individual learning trajectories as a key educational tool in the information society. Smart Digital Futures. Amsterdam: IOS Press BV, 652-657 (2014)

5. R. Bleik, The Messy Task of Evaluating Proficiency in Online Language Courses. Modern Language Journal, 99(2), 408-412 (2015) DOI: 10.1111/modl.12234

6. K. Göransson, C. Nilholm. European Journal of Special Needs Education, 3(29), 265 280 (2014) DOI: 10.1080/08856257.2014.933545

7. A. Nawaz, Z. K. Muhammad, Issues of Technical Support for e-Learning Systems in Higher Education Institutions. MECS Press, 4(2), 38-44 (2012) DOI: 10.5815/ijmecs.2012.02.06.

8. A. T. Mohr, D. Holtbrügge, N. Berg, Learning style preferences and the perceived usefulness of e-learning. Teaching in Higher Education, 17(3), 309-322 (2012) 
9. M. A. Peters, P. Jandric, Dewey`s Democracy and Education in the age of digital reason: the global, ecological and digital turns. Open Review of Educational Research, 4(1), 205-218 (2017) DOI: https://doi.org/10.1080/23265507.2017.139529016.

10. O. Schneider, A concept to simplify authoring of adaptive hypermedia e-learning structures. Interactive Learning Environments, 26(6), 760-775 (2018) DOI: https://doi.org/10.1080/10494820.2017.1412987.

11. M.-C. Tsai, C.-W. Tsai, Applying online externally-facilitated regulated learning and computational thinking to improve students' learning. Universal Access in the Information Society, 17(4), 811-820 (2018) DOI: https://doi.org/10.1007/s10209-0170542-z.

12. K. A. Jones, R. S. Sharma, An experiment in blended learning: Learning without lectures. IEEE Conference on e-Learning, e-Management and e-Services (IC3e), 1-6 (2017) DOI: https://doi.org/10.1109/IC3e.2017.8409229.

13. Q. Wang, C. Huang, Pedagogical, social and technical designs of a blended synchronous learning environment. British Journal of Educational Technology, 49(3), 451-462 (2018) DOI: https://doi.org/10.1111/bjet.12558.

14. R. S. Baragash, H. Al-Samarraie, Blended learning: Investigating the influence of engagement in multiple learning delivery modes on students' performance. Telematics and Informatics, 35(7), 2082-2098 (2018) DOI: https://doi.org/10.1016/j.tele.2018.07.010.

15. I. V. Suvorova, Models of distance education of children with disabilities in Russia. The Education and science journal, 1(1), 90-102 (2014) DOI: 10.17853/1994-56392014-1-90-102. 